\title{
KEY SUCCESS FACTOR OF SPAS - INTERVIEWS WITH LEADERS IN THREE SPA TOWNS IN HUNGARY
}

\author{
Ernő KOVÁCS, PhD, associate professor \\ University of Pannonia, Georgikon Faculty \\ Address: $\quad$ H-8360 Keszthely, Deák F. u. 16 \\ Phone: $\quad+36-83-545-120$ \\ E-mail: h12725kov@ella.hu
}

Zsuzsanna BACSI, PhD, associate professor

University of Pannonia, Georgikon Faculty

Address: $\quad$ H-8360 Keszthely, Deák F. u. 16

Phone: +36-83-545-366

E-mail: $\quad$ h5519bac@ella.hu

Zsuzsanna LŐKE, PhD, assistant professor

University of Pannonia, Georgikon Faculty

Address: H-8360 Keszthely, Deák F. u. 16

Phone: +36-83-545-162

E-mail: loke@georgikon.hu

Acknowledgement: The research presented in the paper has been co-financed by the European Union through the Hungary-Croatia IPA Cross-Border Cooperation Programme. Project no: HUHR/0901/2.1.3., Project title: The role of health tourism in improving the competitiveness of rural regions in Hungary and Croatia. 


\title{
KEY SUCCESS FACTOR OF SPAS - INTERVIEWS WITH LEADERS IN THREE SPA TOWNS IN HUNGARY
}

\begin{abstract}
Summary
The objective of the present research was to identify the role of health tourism in the competitiveness of three Hungarian counties (Baranya, Somogy and Zala) of the Croatian-Hungarian border area. The key factors of success and criteria for sustainability were to be found in order to help the local decision-makers in their attempts to create a strategy for the development of health tourism. As a part of a large research project the current paper describes the results of a qualitative survey of 21 interviews with mayors, spa managers, and hotel managers, to represent general tourism supply to identify the impacts of health tourism developments on the settlement, the economic and social effects on the local population.

The selection of interviewees was done to ensure, that successful, average, and not really successful spa towns were represented among the locations. Among the possible locations in counties Zala, Somogy and Baranya the interviews were finally conducted in Hévíz, Zalaszentgrót, Nagyatád, Marcali, Harkány and Szigetvár, and, to include a location where planned spa development was not implemented, in the village Somogysámson. Besides, the president of the Hungarian Baths' Association was interviewed, who used to be the director of the Szent András Rheumatic Hospital in Hévíz for a long time. Due to some of the interviewees' nonavailability two additional locations, Letenye and Kehidakustány, were also included to complete the list of interviews. An interview was conducted with the mayor of Somogysámson about an unimplemented spa development plan.
\end{abstract}

The main findings of the research underlined that the number of domestic tourists, and within this wellness tourists, is very low compared to the opportunities. For this reason the further development of domestic tourism is of crucial importance. The reasons for that are partly the prevailing habits, the lack of tourism culture, the lack of recreation culture, and financial difficulties.

The successful, progressive spas are those that have continued their development activities relying on their natural endowments, and responding with their innovations to the current expectations of the market and the environment. They have improved their medical treatments, introduced new machinery and technology, built new sight and fun components in the spa. Financial efficiency was achieved by those who were able to attract a sustainable number of visitors. According to the international literature an attraction with a visitor-centre like establishment (a museum, a fun park, a spa, etc.) will be very profitable after it reached 1 million visitors a year in terms of services sold.

A small spa may be financially viable, if the capacities are well designed and the construction responds to the services demanded, as the example of Nagyatád shows.

An adequate spa town image would definitely be needed for the further development of spas. Balatonfüred and Héviz are the only spas that have started to establish a real spa image in Hungary.

The other important component should be the complete documentation for the patients and the treatments in spas and spa hotels, and the same is valid for wellness and fitness. The client should be informed about the impacts of the treatment on the patient's condition.

The spas that are situated in small settlements do not possess resources for financing more serious marketing actions. They also lack creative groups of staff to develop a long-run strategy for the settlement, and to implement planned development projects. The microregions may be the suitable units to take over this role, but because of too many tasks it is highly questionable whether they are able to carry out such strategic developments.

There is need for setting up a national resource inventory, and certain components of developing this system could be done at research and development teams of the universities. This resource inventory could reflect the endowments of the currently existing spas, their visitor numbers, and their qualities.

One of the most problematic areas of the operation of medicinal spas in Hungary is the issue of support from the National Health Insurance Fund, as the amounts have been the same in the last four years. Without this support the spas would not be able to sustain themselves, but the prices of the treatments should be redefined, this is a crucial aspect of sustainability.

Key words: Spa, interview, competitiveness, development, health tourism 


\section{INTRODUCTION}

As demographic trends underline, the demand for health preservation and recuperation is expected to increase in the long run. Hungary has considerable comparative advantage to satisfy this demand due to the richness and high temperature of its underground water resources. Thermal reservoirs are situated under $70 \%$ of the total land area of Hungary (Aquaprofit, 2007). Health tourism development projects may initiate growth in the construction industry, create new jobs, create a market for small and medium size enterprises and the multiplier effect may be beneficial in the regional and national scale, by diminishing spatial and regional discrepancies. The New Széchenyi Plan (2011) of Hungary puts a great emphasis on supporting health tourism projects, and it is particularly important to utilise these funds in efficient and sustainable projects. The objective of the present research was to examine the conditions of success, in order to utilise the available resources for establishing, extending and modernising facilities in an economically viable and feasible way. The research was aimed at the objective analysis of health tourism development in the Croatian-Hungarian cross-border area, which may result in up-to-date recommendations for the investments in the Croatian side, and the future developments in Hungary (Kovács-Bacsi-Lőke, 2011b). The present paper describes the results of a qualitative survey based on interviews with spa and town leaders in several Hungarian spa towns to gain insight into successful and less successful spa developments. Similar research was carried out in Croatia (Kunst-Tomljenović, 2011) in the border region.

\section{OBJECTIVES AND METHODS}

The general objective of the research was to identify the role of health tourism in the competitiveness of the three Hungarian counties (Baranya, Somogy and Zala) of the CroatianHungarian border area, looking for the key factors of success and criteria for sustainability.

In order to gain a deeper understanding about the impacts of medicinal and wellness tourism several interviews were conducted in a number of settlements of the three counties of Hungary, that are important locations with respect to health tourism, contacting managers and executives of local governments, spa directors, hotel managers. The selection of interviewees was done to ensure, that successful, average, and not really successful spa towns were represented among the locations. Among the possible locations in counties Zala, Somogy and Baranya the interviews were finally conducted in Hévíz, Zalaszentgrót, Nagyatád, Marcali, Harkány and Szigetvár, and, to include a location where planned spa development was not 
implemented, in the village Somogysámson. Besides, the president of the Hungarian Baths' Association was interviewed, who used to be the director of the Szent András Rheumatic Hospital in Hévíz for a long time. In conducting the interviews the main difficulty encountered was that some of the interviewees did not accept our request in spite of many attempts to contact them. The spa directors in Harkány and Hévíz, and the local leaders of Nagyatád were not available for the interviews, so we had to choose two additional locations, Letenye and Kehidakustány, to complete the list of interviews. An interview was conducted with the mayor of Somogysámson about an unimplemented spa development plan. Altogether 21 interviews were conducted for the qualitative analysis.

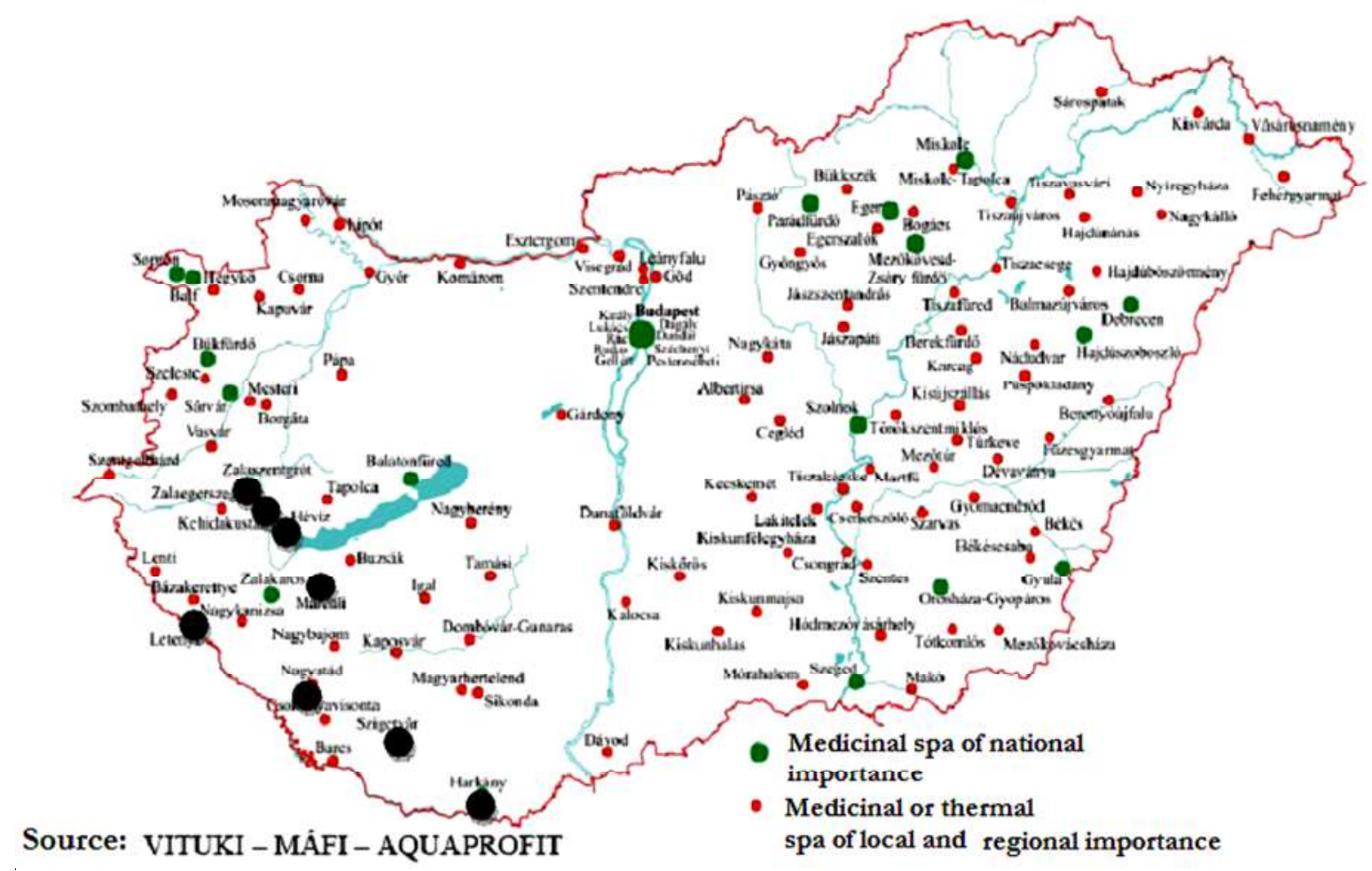

Figure 1: Spas of Hungary, with interview locations

Notation: the location of settlements visited during the primary research is denoted by:

The hypotheses of the research stated that there are a few rules of health tourism, which have to be considered seriously when planning an investment. These are:

- Developments should be focused on complex therapies based on healing water.

- The building of new wellness hotels should not be supported without building a spa together with it.

- The most jobs are created if the medicinal treatments are developed in a spa (because many therapies require considerable manual labour: e.g. massages, physiotherapy, etc.). 
- Each spa should have a unique image, complex facilities of a human scale, where the local products and „hungaricums” can be presented.

\section{RESULTS}

Note: sections printed in italics are direct citations from the interview texts.

\section{Hévíz}

Lake Hévíz is a unique medicinal lake in Europe. The several thousand years old lake over a peat basement is supplied with water from cold and hot springs rich in mineral content, outflowing from an underwater cave $38 \mathrm{~m}$ below the surface. The water supply of 410 liter per second makes the total water volume of the lake completely renew within three days. The temperature of the water is $38.5^{\circ} \mathrm{C}$ at the spring, the lake temperature varies between 24 and $38{ }^{\circ} \mathrm{C}$, depending on the season of the year, making the lake suitable for bathing even in winter. The town Hévíz was the second most popular tourism destination in Hungary, after Budapest, with 931816 guest nights in 2010. The town has purchased $26 \%$ share of property managerial rights in the spa for 340 million HUF. Since then the town has been capable of providing considerable support for spa developments.

\section{Danubius Health Spa Resort Hévíz (the former Thermál Hotel Hévíz)}

This was the first hotel after World War II to provide medical treatments for its guests. It was opened in 1976, and that event is considered the beginning of health tourism in the tourism supply of Hungary. During the past 8-10 years the two hotels of the Danubius chain have been completely renewed, at the cost of 2 billion HUF. The medicinal treatments are based on the medicinal water and medicinal mud of Lake Héviz, and the traditional spa treatments. These are accompanied by the excellent gastronomy supply of the hotel, and, in the latter times, fashionable wellness services, as well as outstanding conference facilities. Unfortunately, due to the global crisis, conference tourism has considerably declined. (Note: In Chapter 4.2 text in italics is applied to indicate quotations from interviews.) 


\section{Kehidakustány}

Besides the spa in Kehidakustány all the other assessed spas are owned by the state or by the local municipality. There are only three privately owned spas in the country, for the sake of comparison. But the other two are open only in the summer season, thus the Kehida Spa is the only privately owned, full service spa in Hungary open all the year round.In the recent years the spa has received annually 400 thousand visitors on average. The proportion of domestic tourists is $99 \%$. An integral part of the spa is the four star hotel, characterised by a low number of rooms. The hotel has 116 rooms, including apartements, special purpose apartements, from the presidential suite to simple rooms. The strength of the hotel is the package of accommodation and many spa services, which are included in the room price. $28 \%$ of the guests pay their bill by holiday vouchers.

Regarding the recent time period the spa has been in the top ten, considering revenues per person. Thus we are good in comparison to competitors in the country. As a short run development project we intend to enlarge the hotel by 50 rooms, and 250 rooms for the long run.

\section{Szigetvár}

The Szigetvár Spa was opened in the 1960s. The water springs from a well of positive pressure, there is no need for suction, its temperature is $67^{\circ} \mathrm{C}$, so the problem is how to cool it. The water became registered as certified medicinal water in 1995. It has several beneficial qualities, it is suitable for drinking cures, there is no sulphurous smell about it, and it is suitable for bottling as medicinal water. Among many diseases the water is effective to treat psoriasis, too.

It is enough to wash the diseased area. The effective agent is active this way. The water can be used in a basin; there is no need for a pool. The mineral content can be distilled, and then people can take it home and use in their bath.

Before the war in the former Yugoslavia the spa had many visitors, but since then it was unable to regain its former attraction. The new spa was completed in 2007 , and cost nearly 1 billion HUF for the town budget. The planned costs of implementation were 829 million HUF, in which 200 million was support, but the final costs nearly doubled. The annual number of visitors used to be 20-25 thousand people in the old spa. Now the new spa has 150000 visitors a year.

It is not enough that we have constructed a new spa, this has been only the first stage. This should be further developed, to receive more visitors. Especially in summer, that is the season 
when the spa could be made feasible. We have one swimming pool, and we have a small „guitar pool”, a small wellness pool of a unique shape. If we had more visitors, our capacity would be too small to service them. We should make developments, in the direction of a pleasure and fun spa, to keep visitors here in the summer season, not to let them go to Orfü or Sikonda, and to other spas where they can find wellness spa, too, The other thing to do is to improve our medical services. We are currently offering complex services, but our space is too small. We have to enlarge it to receive more visitors.

Among the deficiencies of the spa the lack of indoor children's pool must be mentioned, which keeps away families with children, when the weather does not allow open air bathing. The greatest problem of the town is that the typical tourism form is transit tourism. Regarding the number and quality of events, the town infrastructure and attractions Szigetvár is unable to keep its tourists for several days. There are no concerts, nor night bathing facilities within the spa establishment, that some of the spas regularly organise in Hungary.

\section{Zalaszentgrót}

It has been an old wish of the town to have a spa. So the town did its best to achieve this aim. The construction of the outdoor pools was initiated in 2000. The small open-air town pool was built then. At the same time the town applied for funding in the Széchenyi Plan in 2002, and their application was approved, they received funding and built up the indoor pools, too. The total investment cost about 1 billion HUF, together with the well, the required mechanization and equipment, and infrastructure. The support provided by the Széchenyi Plan was 160 million HUF, another 50 million HUF was provided by the county of Zala for the development, and another 50 million HUF by the region.

The thermal spa opened in 2001, then in 2003 the second stage of the spa was completed, adding an indoor unit with 4 pools and a fun pool to the establishment. In 2009 the energy supply was modernised, leading to a decrease in the share of fossile fuel consumption. From 2009 the spa has been run by the Szentgróti Water and Spa Ltd. (Szentgróti Víz és Fürdő $\mathrm{Kft}$.), and this company is the owner of the spa, too, while the $100 \%$ ownership of the company belongs to the Local Government of Zalaszentgrót.

The spa is considered to be a medium size spa in the region. The following table shows, that in the first and second years after its opening, when the spa was a new attraction in the area, the number of visitors was 84-82 thousand a year, but since that time the number of visitors has decreased nearly every year, and in 2009 only 52 thousand people visited the spa. 
This pattern has been perceived with other spas, too, that following the first few years of operation the number of visitors keep decreasing. Some experts of the field say, that this is explained by the lack of continuous developments, the lack of a unique image, and the loss of the novelty of the spa's existence.

Table 1. Visitor numbers in the Zalaszentgrót spa, 2005-2009

\begin{tabular}{|r|c|c|c|c|c|}
\hline & $\mathbf{2 0 0 5}$ & $\mathbf{2 0 0 6}$ & $\mathbf{2 0 0 7}$ & $\mathbf{2 0 0 8}$ & $\mathbf{2 0 0 9}$ \\
\hline Visitors (person) & 84000 & 82000 & 76000 & 60000 & 52000 \\
\hline Gross revenues (million HUF) & 58 & 66 & 66 & 58 & 56 \\
\hline
\end{tabular}

Source: data provided by the Spa Management in Zalaszentgrót

The spas themselves usually employ only a few people, if they do not provide medical treatments, and in Zalaszentgrót the spa employs only 16 persons. The capacity of the spa in the autumn and winter seasons is under-utilised. The spa is currently a thermal spa and not a medicinal one. It does not receive diseased people financially supported by the National Health Insurance Fund (OEP). This is one of the main reasons of the low number of visitors. In 2009 the spa started to accept holiday vouchers as payment, and 5.6\% of the visitors - and already $11 \%$ in 2010 , up to the date of the interview - paid by the services using a holiday voucher.

\section{Nagyatád}

The spa in Nagyatád is the oldest known spa in county Somogy. It was opened in 1906 for the public. The water contains sodium-hydrocarbons, alkaline - containing mineral salts of $1400-1500 \mathrm{mg}-$, and due to its composition it is effective to treat skin diseases, digestive problems, problems of the respiratory system, of the musculo-skeletal system, gynecological disorders. In Nagyatád there is no time limit specified for bathing, visitors can stay longer than 20 minutes, which is the recommeded limit in Lake Hévíz.

It used to be a spa before the war, it was bombed down during the war, then reconstructed. The developments started in the 1970s, and their focus was on medicinal treaments. From then on medical staff and a physician have also been employed. It must be mentioned that there has always been a phyisician in the microregion, and we have an employee who has been working here for 40 years, since the opening of the spa, now preparing to retire from here. 
The Nagyatád Thermal and Medicinal Spa opened in 1989 has a capacity to receive 2 thousand persons, in an area of 2 hectares. It was renovated in 2006.47 persons work in the spa. The Nagyatád Spa has all facilities that other medicinal spas have in Hungary, thus it provides all components of the 10 treatments supported by the National Health Insurance Fund, only the capacity is smaller. Altogether 86 thousand visitors are received a year in the spa, the number has been stagnating for the last years, because the capacity is limited. $30 \%$ of the visitors are supported by the National Health Insurance Fund. Besides the spa the town also has an open-air swimming pool complex, with a $50 \mathrm{~m}$ swimming pool suitable for championships, a thermal jacuzzi pool, a childrens' pool, and an fun pool with water chutes.

The spa has three medicinal pools and 5 bathtubes for those coming to heal or for prevention. Besides the bathing therapies and the drinking therapies additional medicinal and wellness treatments are offered, too.

\section{Marcali}

The thermal spa of Marcali opened in 2003. At that time, only the outdoor facilities were operating, in 2003 the spa was open only for 1.5 months, and from 2004 to 2008 it operated 5 months each year. Then a modern educational swimming pool unit was built in a PublicPrivate Partnership (PPP) contruction that opened on $22^{\text {nd }}$ August 2008. From then on the spa has been open all the year round. In summer the open-air facilities are open for 4 months, there is no demand for more. The indoor educational pools are open throughout the year, except for a one week break for mandatory water exchange, done twice a year. During the school year 14 schools send students to swim here. This means that from Monday to Friday the educational pools and swimming pools are busy with schoolchildren from 8 a.m. to 3 p.m. After 3 p.m. the kindergarten pupils, the handicapped children and the disadvantaged children use the pools. Thus in weekdays from morning to $5 \mathrm{p} . \mathrm{m}$. the pools are utilised to their capacities. In 2007, when the spa was open only in summer, the number of visitors was 30000. Last year 52000 visitors and 16000 student visitors were recorded. Currently the spa has three hot wells, two of which provide certified medicinal water; one of them received the cerificate as early as in 1989. The second well received the certificate in the spring of 2011. The third well is under assessment for the certification.

The medicinal water is effective for disorders of the musculo-skeletal system. The water of one well is effective for gynecological complaints, primarily for the inflammations of the pelvis area. 
The spa utilises renewable energy as an enery source. The heating and the temperature maintenance of the pools, and the hot water are provided by heat pumps. The ventilation system also works by the heat pump system. There are dry capsule wells around the building to circulate the liquid, the temperature of which is $14-15^{\circ} \mathrm{C}$, when it emerges to the surface, and only a few degrees when it returns. The efficiency of the heat pump is about $400 \%$. It can be said a modern system in this respect. The system lowers the operational costs of the establishment considerably.

In the PPP programme an external partner has built up the establishment, and will run it for 15 years, half of the operational costs are covered by the municipality, the other half by the state.

I can tell you by the experiences so far, that this financing system works. The main motivation of establishing these pools was the public purpose utilisation. This is about 80\% now, and above, which is remarkably good.

In 2010 two developments were carried out. A new pool of medicinal water was built, which was opened in August, and contains 15 fun components. Besides the pool a water chute was established, with remarkable success attracting many visitors, especially children. Considerable technological improvements were also made. An old cold-water well was reopened to water the spa area. Up to now each year about $4000 \mathrm{~m}^{3}$ was used for watering. With this well the former cost of $800 \mathrm{HUF} / \mathrm{m}^{3}$ decreased to a mere 60 to $80 \mathrm{HUF} / \mathrm{m}^{3}$.

\section{Harkány}

The water of Harkány is effective not only for rheumatic, gynecological and rehabilitational problems, but to treat psoriasis, a skin disease frequent mainly in the Northern states (Norway, Sweden, Finland, Denmark). Besides the Spa the Harkány Rheumatism Hospital also provides treatment for this disease.

The spa is situated in an enormous area, compared to other Hungarian spas, - 13.5 hectares, with $2098 \mathrm{~m}^{2}$ water surface. The therapies in Harkány show impressive results in the prevention or treatment of osteoporosis, musculo-skeletal disorders, chronic gynecological inflammations, and disorders of the lymphatic system.

Altogether 230 persons work in the spa itself. Besides, the food and beverage serving units, and accommodations serving the spa visitors also give jobs to many people. The spa provides the living for many families in Harkány. But the spa gives jobs not only to the residents of the town. Approximately $50 \%$ of the employees live elsewhere. This is necessary, because the 
spa requires specially trained labour in the medical departments. Besides, the Rheumatic Hospital also employs a large specially trained staff. As the majority of people can go to special treatments only at the weekends, the medical department and the spa are open during the weekends, too. This requires higher numbers of staff.

During the history of the spa ownership has changed hands several times. Initially the spa was entirely owned by the town. Then it was owned by the county and the state. Then $90 \%$ $100 \%$ of the ownership went to private hands. Later, at the beginning of the 1990s a series of court trials led to the shared ownership of $50-50 \%$ for the Baranya County Local Government and for the town of Harkány. On $21^{\text {st }}$ September 2006 the town purchased the shares of the county for 1.65 billion HUF, thus attaining 100\% ownership. To finance the purchase the town took a credit, and the repayment of which starts in 2011. Since 2008 the economic recession and crisis has made difficulties for the local government, so the repayment is likely to cause problems. The continuous changes also gave rise to conflicts.

There have been conflicts. During the developments financial difficulties have arisen. There were times, when the town had problems with the management of the spa. That is, with the appointed staff and the operation itself. After the purchase in 2006 these were sorted out. There have been no problems since.

The spa was completely renovated in 2004. The reception building and the pools have been refurbished. The two large pools have got an indoor and an outdoor part, too. They are entirely modern, technologically up-to-date. At the top floor of the reception building a 'viewpool' was established, with jacuzzi, sauna, solarium as well.

The reconstruction of the spa in Harkány generated new investments as well. The already existing hotels were also reconstructed, renovated. Some of them has a small amount of medicinal water, which is used in small pools and basins. The newly built apartement houses, boarding houses have been constructed to satisfy the demand by visitors coming for the spa.

Without the spa Harkány would be just an ordinary settlement, like many others in the country. Because 183 years ago this wonderful healing water was found, the settlement has attained impressive progress by now.

\section{DISCUSSION}

Currenty the number of domestic tourists, and within this the wellness tourists, is very low compared to the opportunities. For this reason the further development of domestic tourism is of crucial importance. The total number of guest nights at commercial accommodations was 19031 in 2010 in Hungary according to preliminary data by the Central Statistical Office. The 
number of domestic tourists has slightly increased, being only $2 \%$ higher than that of the very low figure of 2009 , while the number of foreign tourists has grown by $5 \%$. The support for the holiday voucher, a component of the cafeteria system offered by public employers and the state-owned companies is large, while in the private sector only multinational companies use support for tourism, recreation and relaxation as tools of employee motivation.

I am saying that really 1.2 million Hungarians are active participants in domestic tourism, the others are either passive, or completely deny the possibility of participating ever. declared the owner of Kehida Thermal.

The reasons for that are partly the prevailing habits, the lack of tourism culture, the lack of recreation culture, and financial difficulties. About 2 million Hungarian employees have not enough disposable income to take part in domestic tourism. An attainable long run target could be to raise the volume of domestic tourism to $300 \%$ of the current level, by introducing a Recreation Card, or other incentives. If society took this aim seriously, then it would have considerable positive impacts on the national economy (by rising employment and GDP, etc.). The increasing levels of domestic tourism would create a sound basis for inbound tourism, too. Currently the proportion of domestic tourism to inbound tourism is $60 \%$ to $40 \%$. This is the opposite of typical proportions in other countries. Without this paradigm change no significant development can be expected in tourism.

\section{The characteristics of successful spas}

Success or failure in Hungary after 1945 depended on the views of the leader, the town or settlement, or the company that operated the spa, whether they looked at tourism as a possible successful greenfield investment, and whether they were willing to allocate sufficient funding for development.

Spa developments started together with the re-evaluation of the spa culture itself. This process went through several stages. The first wave occurred in the 1960s. At that time many new spas were built. The next stage came in 1978, at the time of the great thermal project, when the capacities and opportunities of health tourism were evaluated in Hungary. After that the Széchenyi Plan offered funding for project proposals, then the investments of the New Hungary Development Plan, and later of the New Széchenyi Plan.

The successful, progressive spas are those that have continued their development activities relying on their natural endowments, and responding with their innovations to the current expectations of the market and the environment. They have improved their medical treatments, introduced new machinery and technology, and built new sight and 
fun components in the spa. Financial efficiency was achieved by those who were able to attract a sustainable number of visitors. According to the international literature an attraction with a visitor-centre like establishment (a museum, a fun park, a spa, etc.) will be very profitable after it reached 1 million visitors a year in terms of services sold.

Considering the success of a spa, then currently it is of absolutely no relevance, whether other attractions exist or not besides the spa. The real great success would be to have a complex medical treatment based on the medicinal water. If this is unique, then people would go there. If someone had a pain, and he/she knows that the spa is an effective remedy, then.... this person would return.

The places that made progress were those which recognised their unique endowments and based continuous developments on these endowments. At the same time they constantly tried to respond to the challenges of the market. If needed, then with marketing, or with development or with training. Those who stopped, have fallen behind in the competition. Successful places may be large or small. If developments were done consciously, the spa progressed.

There are spas that suddenly produced a striking growth, being novelties in their areas, then they were unable to maintain this growth, and without further development they lost their market and growth potential. This happened probably because of problems with visitor management. Harkány can be mentioned as an example.

A small spa may be financially viable, if the capacities are well designed and the construction responds to the services demanded. Nagyatád is a small spa in a small town, but it receives nearly 100 thousand visitors a year.

An adequate spa town image would definitely be needed for the further development of spas. This refers to the buildings and the traffic and transport system, the infrastructure adequate for the services, and the positive attitude of the local community towards tourists. This also includes everything related to the medicinal water, from certifications to the training of the staff. About 100 years ago a spa was designed by the architect in full with all its components. This included the house of the gardener, the glasshouse where the summer flowers were kept in winter or new plants were grown. The hotels and the director's home, the spa, the parlour, the halls, the garden, the promenade, and everything were included. It was not like now, planning only the spa and nothing else. Planners worked in a different way in the past. The spa was planned together with all the ancillary components; everything in the same style. Festetics planned Hévíz in the same way. Documents show it in the archives. Today this would include the height limits, pollution criteria, noise, light and advertisements, 
as well as the public security and sanitary safety. Of course there are a thousand details: safety of the pools, operational safety, guest safety, various standards, water technology, roads, etc. If all these are considered, Hungary has no settlements of a spa image. There are good attempts to attain this in Füred and maybe the town centre in Héviz.

Balatonfüred and Héviz are the only spas that have started to establish a real spa image.

The other important component should be the complete documentation for the patients and the treatments in spas and spa hotels, and the same is valid for wellness and fitness. The client should be informed about the impacts of the treatment on the patient's condition.

In Germany spas stopped using natural medicinal water. All waters are biologically or chemically cleared and treated. (On the contrary, the spa water in Sárvár is cleared in a natural way.) The Danubius hotels in Hévíz, and a few medicinal spas use filtered natural medicinal water. It is natural, chemically and biologically active medicinal water, free of bacteria and viruses. This is a great opportunity for Hungary to provide medication to more sick people. According to findings by Spanish researchers the chlorine-treated waters of swimming pools may create an enhanced risk of cancer. „The researchers of the Centre of Research in Environmental Epidemiology (CREAL) and the Hospital del Mar have proven genotoxic impacts in 49 healthy adults, after swimming for 40 minutes in a cloride-treated indoor pool. The researchers of the CREAL examined people who were swimming in chlorine-treated pools. Their results showed mutations in the DNS molecules of every swimmer." The study was published in the professional journal Environmental Health Perspectives (HVG 2010).

The spas that are situated in small settlements do not possess resources for financing more serious marketing actions. They also lack creative groups of staff to develop a long-run strategy for the settlement, and to implement planned development projects. The microregions may be the suitable units to take over this role, but because of too many tasks it is highly questionable whether they are able to carry out such strategic developments.

There is need for setting up a national resource inventory, and certain components of developing this system could be done at research and development teams of the universities. This resource inventory could reflect the endowments of the currently existing spas, their visitor numbers, and their qualities. Similarly to the development concept of the UNO Thermal Project, a professional team of experts could advise on what to develop (roads, environment, etc. ) at various locations.

If we made up our minds to decide that the real Hungarian profile is a profile of medical treatments, and then tried to segment our medicinal waters, like waters of gastro-enterology 
type, or of musculo-skeletal type, this water for this disorder, that for that. Or even if the water is not so specific, the services and activities of the medical institution should be specialised into a particular area, so that it offers a unique series of services. Somewhere this could be sports injuries, somewhere childrens therapies, etc. Then, perhaps, the definite component of the supply would not be the quality of the water, but the message about it for the target group. And of course, if some of the thousand medicinal and thermal wells give a really outstanding water, that is worth developing, then that must be developed.

One of the most problematic areas of the operation of medicinal spas in Hungary is the issue of support from the National Health Insurance Fund, as the amounts have been the same in the last four years. Without this support the spas would not be able to sustain themselves, but the prices of the treatments should be redefined, this is a crucial aspect of sustainability. If the support from the National Health Insurance Fund is paid at low, artificial prices, then the spas will also lose the competition in the national market.

\section{CONCLUSION}

The objective of the present research was to assess the competitiveness of health tourism in the Croatian-Hungarian border region, in three counties of the Croatian, and three counties of the Hungarian side. The research was intended to identify the economic and social impacts of health tourism developments on people and enterprises working in health tourism or in related areas, employees of enterprises and health care institutions, local inhabitants and local governments. Health tourism is a sector in the economy which can continuously generate high incomes and tax revenues in successful health tourism destinations that supply competitive services. The global crisis of 2008-2009 showed, that although the tourism sector considerably suffered from the negative effects of the crisis, health tourism has hardly felt this negative impact. Relying on the findings of the analyses the following recommendations may be made to enhance the success of future developments:

\section{Aspects of water quality and medical treatments:}

- Complex and unique medical treatments are needed, based on the features of medicinal waters. Harmonised examination principles should be introduced in all the spas of the region or the country, which follow the patient from admittance to the spa till leaving, supplemented by comprehensive documentation on the treatments applied. This should be implemented for medical, wellness and fitness treatments alike. 
- Research should be carried out to provide scientific evidence for the effectivity of medicinal waters. Only the scientifically justified effects can be presented in promoting the spa, so the detailed and thorough assessment of the water-based therapies is needed, as well as documentation of these research results, to communicate them towards the consumers.

- The establishment of a national scale of quality assurance as soon as possible, to provide a sound background for the top quality spa services.

- Besides bathing and therapies, thermal waters should be utilised in alternative ways - e.g. as energy sources, so that health tourism institutions can be made more cost-efficient.

- Monitoring is needed to protect sub-terrain water resources against excess exploitation and pollution.

\section{Planning the establishment of accommodation and investments, resource utilisation}

- The spa developments and hotel construction should be compatible. Wellness hotels should not be constructed without spas and spa developments should not be supported without adequate accommodation facilities, to allow for optimal efficiency in utilisation. The quality level of the spa should correspond to the quality level of the hotel, so that consumers meet the same quality standards at both places.

- The development of the medical treatments unit is the most important factor of competitiveness, and it leads to the largest increase in new jobs (many therapies, as massages, physiotherapy treatments require manual work).

- The full range of training should be established to correspond to the job requirements in spa services (especially tertiary training for pool maintenance experts is needed currently).

- For green-field investments a complex development concept should be designed with all the conditions and possibilities of expansion needed for efficient operation in the future. In every second or third year new attractions should be established for returning visitors.

- As one-day visitors come from about $20-30 \mathrm{kms}$ distance, the accessibility of the spa and parking facilities are very important for them.

- The settlement should establish and possess the atmosphere and image of a spa town by adding and developing other tourism attractions beside the spa. 
- The development of renewable energy utilisation should be preferred in spa developments and reconstructions, as well as other forms of utilising thermal water (including the heating of the spa and hotel, residential heating hot water systems, agricultural purposes).

\section{Marketing activities, reaching the target consumer group}

- A powerful international marketing concept should be built up for the complex, modern physiotherapy and balneotherapy, that is, for the complex therapy based on the medicinal water. In this marketing message the supply of health care, prevention and rehabilitation services should all be promoted. The foreign marketing message should be country-specific, corresponding to the demands of the target audience. Separate brochures should be provided for doctors, patients and guests, according to their interests.

- Spas should have a unique image, at a human scale, where the local, „hungaricum” products can be also offered to customers.

- The suitable marketing message is the promotion of medical therapies for the elderly clients, and the amusements and enjoyments for the younger generation, who usually visit spas for exactly these purposes. It is important to extend regularly the supply of the spa by new components for the returning visitor.

- The visitors, when making the decision about visiting a spa, rely primarily on their past experience or the personal information from relatives and friends, as well as on the internet, so the promotion and marketing channels should be designed accordingly.

- As the area under assessment lies around the border, marketing should be strengthened towards the tourists from neighbouring country (Croatia), knowing that not only the border region, but the capitals of bearby countries may be important markets, as Zagreb, Vienna, Ljubljana, Bratislava. Hungarians do not know the health tourism supply of Croatia. Although Croatian citizens know Hungarian spas better, still the inhabitants of both countries visit the other country mainly for relaxation and shopping. There are opportunities to expand connections, to promote spa and leisure tourism, as well.

\section{Action by national and municipal authorities}

- More active government involvement is needed to make the spa treatments of Hungary recognised by the health insurance institutions in EU countries (initial steps have 
been taken), and further research is needed on the effects of thermal waters, and a uniform price system to be established.

- A national resource inventory should be set up for the currently running spas, tourist arrivals and quality of services. These are needed to define the priorities of development.

- The utilisation of tax revenues related to tourism, and the tourist tax in particular, should be regulated, relying on the good practices in Austria and Switzerland.

- The cooperation between settlements and spas should be enhanced, the common interest recognised and prioritised, debates about ownership and utilisation rights settled.

The authors express their gratitude to all, who, by participating in the interviews, shared their experiences with them, thus contributing towards the success of the present research

\section{LITERATURE}

1. Aquaprofit Rt. (2007): Országos egészségturizmus fejlesztési stratégia. Budapest.

2. Kovács, E.; Bacsi, Zs.; Lőke, Zs. (eds, 2011a): The Role of Health Tourism in Improving the Competitiveness of the Croatian-Hungarian Border Region. Balatoni Integrációs Közhasznú Nonprofit Kft, Siófok (Hungary)

3. Kovács, E.; Bacsi, Zs.; Lőke, Zs. (2011b): Healing - Pleasure - Competitiveness: Empirical Assessment of the Spa Settlements in Baranya, Somogy and Zala counties. In: Kovács, E. ; Bacsi, Zs.; Lőke, Zs. (eds, 2011): The Role of Health Tourism in Improving the Competitiveness of the Croatian-Hungarian Border Region (pp. 39-76). Balatoni Integrációs Közhasznú Nonprofit Kft, Siófok (Hungary)

4. Kunst, I.; Tomljenović, R. (2011): The role of health tourism in improving the competitiveness of rural areas in the Republic of Croatia (pp.77-118). In: Kovács, E. ; Bacsi, Zs.; Lőke, Zs. (eds, 2011): The Role of Health Tourism in Improving the Competitiveness of the Croatian-Hungarian Border Region (pp. 39-76). Balatoni Integrációs Közhasznú Nonprofit Kft, Siófok (Hungary)

5. VITUKI - MÁFI - AQUAPROFIT (2007): Magyarország termál- és gyógyfürdői térkép. In: Aquaprofit Rt. (2007): Országos egészségturizmus fejlesztési stratégia. Budapest. 